\title{
Monitoring bond-slip behavior of CFRP-RCESC beams using piezoelectric active sensing method
}

\author{
Tianyong Jiang ${ }^{1}$, Donghai $\mathrm{Yu}^{1}$, Min Xiao ${ }^{2}$, Lingyun $\mathrm{Li}^{1}$ and Lei Wang ${ }^{1 *}$
}

\author{
*Correspondence: leiwang@csust. \\ edu.cn \\ ${ }^{1}$ School of Civil Engineering, \\ Changsha University of Science and \\ Technology, Changsha, China \\ Full list of author information is \\ available at the end of the article
}

\begin{abstract}
Combination of carbon fiber reinforced polymer (CFRP) tendon and reinforced concrete encased steel composite (RCESC) beam can improve the workability and the energy dissipation capacity of members. In this paper, three RCESC beams reinforced with steel bars or CFRP bars were designed and fabricated to study the bond-slip behavior between I-shaped steel and CFRP reinforced concrete and the damage states between bond-slip interfaces of the beams. The lead zirconate titanate (PZT) patch as stress wave actuator, the smart aggregates (SAs) were installed in concrete as the sensors to collect the stress wave signal. A method based on piezoelectric active sensing was developed to monitor the bond-slip damage of CFRP-RCESC beam. The changes of responding signals were characterized in timeand frequency- domains. The characteristic information of bond-slip damage was further quantified by wavelet packet energy. Results show the bond-slip resistance of the CFRP-RCESC beams can be improved by increasing reinforcement ratio and elastic modulus of the main bars. The bond-slip damage process of the specimens can be effectively monitored by the active sensing method.

Keywords: Bond-slip damage, CFRP-RCESC beam, Lead zirconate titanate (PZT), Smart aggregates (SAs), Wavelet packet energy, Active sensing method
\end{abstract}

\section{Introduction}

The reinforced concrete encased steel composite (RCESC) beam has been widely used in long-span bridges (T. Jiang et al. 2017; Y. Chen et al. 2017), super highrise buildings (C. C. Weng et al. 2002), and aseismic structures (A. Jiang et al. 2013; C. C. Chen et al. 2018), due to its low height and dead weight, satisfactory ultimate bearing capacity and fireproof performance. However, the corrosion of steel bars in reinforced concrete structures leads to serious structural safety problems. Carbon fiber reinforced polymer (CFRP) reinforcement is considered to a promising method to overcome safety problems (Martinelli et al. 2014). CFRP reinforcement has the advantages of high strength, low mass and elastic modulus, low-cost and excellent corrosion resistance (Ge et al. 2019). The combination of CFRP bars and RCESC is an effective method to improve the ductility and

(c) The Author(s). 2021 Open Access This article is licensed under a Creative Commons Attribution 4.0 International License, which permits use, sharing, adaptation, distribution and reproduction in any medium or format, as long as you give appropriate credit to the original author(s) and the source, provide a link to the Creative Commons licence, and indicate if changes were made. The images or other third party material in this article are included in the article's Creative Commons licence, unless indicated otherwise in a credit line to the material. If material is not included in the article's Creative Commons licence and your intended use is not permitted by statutory regulation or exceeds the permitted use, you will need to obtain permission directly from the copyright holder. To view a copy of this licence, visit http://creativecommons.org/licenses/by/4.0/. 
durability of this component (Zheng et al. 2018a). The CFRP reinforced concrete encased steel composite (CFRP-RCESC) beam has achieved a significant enhancement in ultimate bearing capacity and energy dissipation capacity (Li et al. 2011; D. Yao et al. 2014).

Numerous researches have shown that the combination of CFRP and RCESC can effectively improve the workability and energy dissipation capacity of these components. However, the bond-slip damage is easy to occur between steel flange and concrete because of the defects of construction quality, temperature change and the overweight and overload during service life (Y. Chen et al. 2017; C. C. Chen et al. 2018). The experimental and theoretical analysis results show that the bond-slip damage can greatly weaken the ultimate bearing capacity of concrete encased steel composite beams (Brisotto et al. 2012; L. Z. Dai et al. 2021; L. Chen et al. 2015). The bond-slip behavior and damage monitoring in civil engineering have attracted much attention from researchers and engineers. A study by Kim et al. (2013) pointed out that adding fiber material changed the bonding behavior of concrete structure, leading to a significant increase in bond strength. Majdi et al. (2014) proposed a novel drawing test method and discussed the bond-slip behavior of galvanized cold-formed steel in ordinary strength concrete of ordinary weight. Zhang et al. (2020) studied the bond behavior between Engineering Cementitious Composites (ECC) and Glass Fiber Reinforced Polymer (GFRP) bar composite structure, that the Poisson's effect can be reflected in the reduction of the bond strength of ECC and GFRP.

The structural health monitoring methods used for bond-slip damage mainly include acoustic emission technology (A.A. Abouhussien et al. 2017), ultrasonic method (M. Rucka. 2018), method based on optical fiber sensor and active infrared thermography (S.C.M. Ho. 2015; S. Hiasa. 2016; J.B. Renshaw et al. 2015), etc. However, most of the above methods cannot monitor the whole process of bond-slip and quantify the damage extent. Piezoelectric ceramic sensors based on the lead zirconate titanate (PZT) have been extensively studied and applied in bond-slip damage monitoring of civil structures (F. Qin et al. 2015; P. Yao et al. 2016; T. Jiang et al. 2018a, 2018b). Additionally, since the embedded PZT transducer, known as smart aggregate (SA), was proposed for more accurate damage detection, the piezoceramic-based active sensing method have shown great reliability in monitoring the bond-slip of steel-concrete composite components (Kong et al. 2016; K. Xu et al. 2018; L. Huo et al. 2018). Jiang et al. (2017) proposed an active sensing method to quantitatively identify bond-slip damage between FRP bars and concrete specimens. P. Giri et al. (2019) proposed a feature extraction method based on piezoelectric transducers to predict the clearance and peeling state.

The results of literature review show that the overall flexural behavior of CFRP-RCES $\mathrm{C}$ beams is well studied, while the internal bond-slip behavior and damage states are less studied. In this study, a stress wave based active sensing approach is proposed to real-time monitor the occurrence and the whole process of bond-slip damage of CFRPRCESC beams. Three concrete encased steel composite specimens were prepared in the test study. The lead zirconate titanate (PZT) patch as stress wave actuator and the smart aggregates (SAs) as the sensors were installed in the specimens. The monitoring signals were analyzed in time domain, frequency domain, and wavelet packet energy. 
The bond-slip sensor was used to monitor the bond-slip behavior between I-shaped steel and carbon fiber reinforced polymer-reinforced concrete.

\section{Experimental material and program}

\subsection{Experimental specimen introduction}

Three specimens were made to monitor the bond-slip damage characteristics of CFRPRCESC beams in this study, five pairs of PZT and SA were embedded in different parts of each specimen, the specimen details are shown in Fig. 1.

There were three test specimens, which were Test Specimen A (TSA), Test Specimen B (TSB) and Test Specimen C (TSC). The PZT patches were mounted on the top or bottom surfaces of I-shaped steel, and the smart aggregates (SAs) as the sensors were installed in concrete about $20 \mathrm{~mm}$ from the PZT patches, their typical cross section is shown in Fig. 2. The main bars of the TSA are the three steel bars with a diameter of $16 \mathrm{~mm}$. The main bars of the TSB are two CFRP bars with a diameter of $10 \mathrm{~mm}$. The main bars of the TSC are four CFRP bars with a diameter of $5 \mathrm{~mm}$.

In the test, each specimen has longitudinally distributed reinforcement with diameter of $12 \mathrm{~mm}$ in the compression zone. The steel stirrup with diameter of $8 \mathrm{~mm}$ is arranged along the length of the specimen at different spacings and the thickness of concrete cover of steel stirrups is $24 \mathrm{~mm}$. The I-shaped steel beam embedded in the center of specimen is a hot-rolled 12.6-I beam, which has a typical cross-section that the depth is $126 \mathrm{~mm}$, the flange breadth is $74 \mathrm{~mm}$, the thicknesses of web and flange are $5 \mathrm{~mm}$ and $8.4 \mathrm{~mm}$ respectively. The elastic modulus and yield strength of I-shaped steel material are 206GPa and $235 \mathrm{MPa}$, respectively.

In this study, the type of the PZT transducer was PZT-5H, which was used as the actuator and sensor with diameter of $7.4 \mathrm{~mm}$ and thickness of $1.3 \mathrm{~mm}$. The SAs were made of two marble pieces protecting a PZT patch with a wired lead, whose dimensions were $25 \mathrm{~mm} \times 25 \mathrm{~mm} \times 25 \mathrm{~mm}$. The concrete encased steel composite beam was made of ordinary Portland cement of grade 42.5, the mix proportions of concrete were given in Table 1. The elastic modulus of CFRP bars is 147GPa, and its ultimate tensile strength is $2550 \mathrm{MPa}$. Besides, the elastic modulus and ultimate tensile strength of HRB400 steel bars and stirrups are 200GPa and 330MPa, respectively (Jiang et al. 2017; Wang et al. 2019).

In this study, TSA and TSB have the same flexural capacity, but the elastic modulus of the main reinforcement is different. TSB and TSC have the same

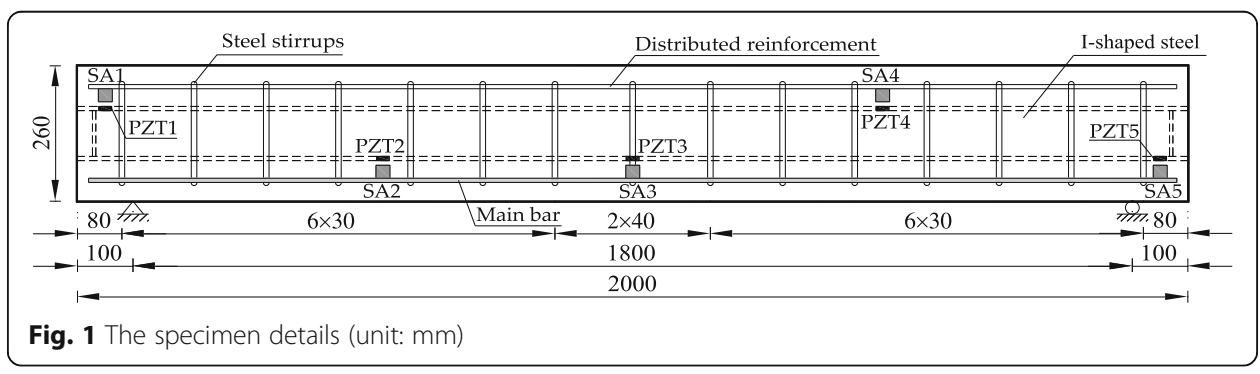




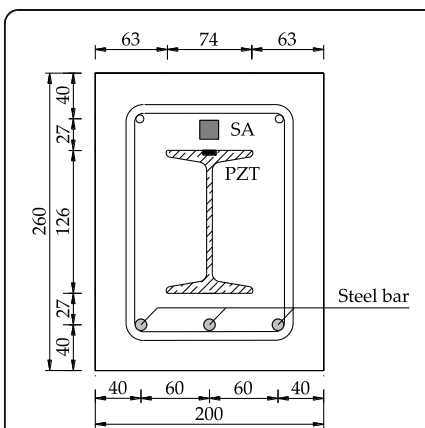

(a)

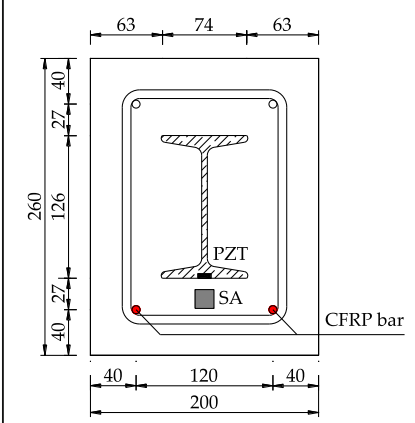

(d)



(b)

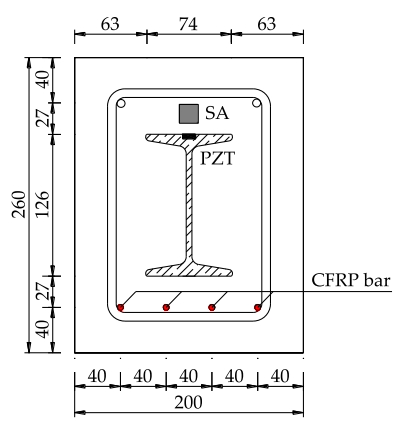

(e)

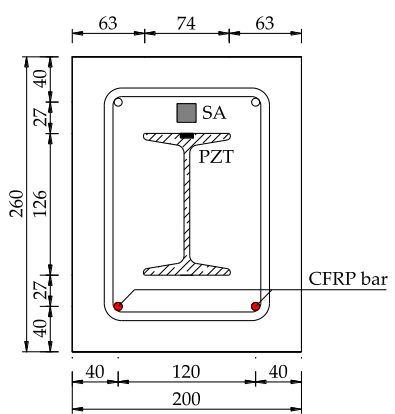

(c)

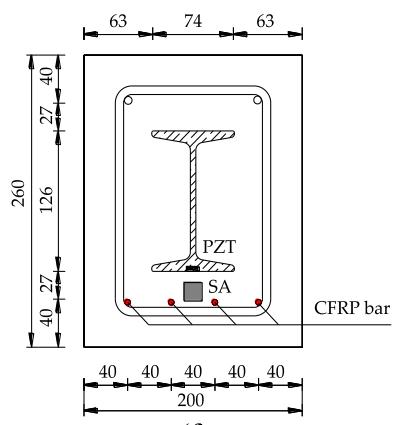

(f)

Fig. 2 Typical cross-sections of the specimens (unit: $\mathrm{mm}$ ). a: The left end or right quarter span cross-section of TSA, $\mathbf{b}$ : The right end, mid-span or left quarter span cross-section of TSA, $\mathbf{c}$ : The left end or right quarter span cross-section of TSB, $\mathbf{d}$ : The right end, mid-span or left quarter span cross-section of TSB, e: The left end or right quarter span cross-section of TSC, $\mathbf{f}$ : The right end, mid-span or left quarter span cross-section of TSC

elastic modulus and contact area between CFRP bars and concrete, but the arrangement of bars is different. Therefore, this experimental study will achieve the following research objectives: (1) Monitoring the effect of elastic modulus of main reinforcement in steel bar or CFRP bar reinforced concrete encased steel composite beam for bond-slip damage, such as TSA and TSB. (2) Monitoring the effect of the distribution characteristics of main reinforcement in CFRP- RCESC beam for bond-slip damage, such as TSB and TSC.

\subsection{Experimental equipment and procedures}

The test setup is shown in Fig. 3. The bond-slip between two ends of I-shaped steel and concrete was monitored by two bond-slip sensors. Five dial indicators were embedded at various key locations in the specimens to measure the deflections of test specimens. One data acquisition board NI-USB 6363 was used to monitor damage signals by connecting to one laptop computer with supporting software.

Table 1 Mix proportions of concrete

\begin{tabular}{lllll}
\hline Cement $\left(\mathbf{k g} / \mathbf{m}^{\mathbf{3}}\right)$ & Water $\left(\mathbf{k g} / \mathbf{m}^{\mathbf{3}}\right)$ & Sand $\left(\mathbf{k g} / \mathbf{m}^{\mathbf{3}}\right)$ & Stone $\left(\mathbf{k g} / \mathbf{m}^{\mathbf{3}}\right)$ & Water reducing agent $\left(\mathbf{k g} / \mathbf{m}^{\mathbf{3}}\right)$ \\
\hline 325 & 180 & 769 & 941 & 12.5 \\
\hline
\end{tabular}






Fig. $\mathbf{3}$ Test setup

The bond-slip sensor was installed on the end of the test specimens, which can obtain the relative bond-slip between I-shaped steel and concrete, as shown in Fig. 4.

The loading process was divided into two stages of preload and load tests. Before loading test, the gap between the loading device and the beam specimen should be eliminated to ensure that the loading device and the test equipment were in promising condition. In the loading test, the load of the screw jack was measured by the force sensor, and the load was read by the force strain gauge. The static load increased at a rate of $20 \mathrm{kN}$ per stage till the damage of the test specimen occurred. The bond-slip sensors continuously recorded the relative bond-slip between the upper flange of I-shaped steel and the concrete at a period of $5 \mathrm{~s}$. After the force of each loading stage came to be stable, the performance parameters of the test specimen were tested, such as the test specimen crack, the vertical displacements, the stress wave signals.

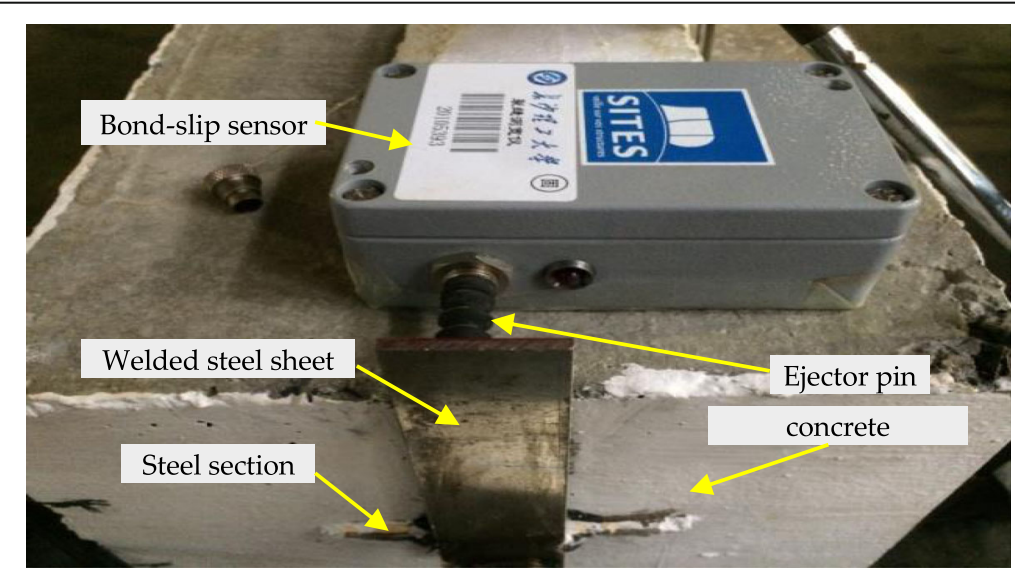

Fig. 4 Bond-slip sensor setup 


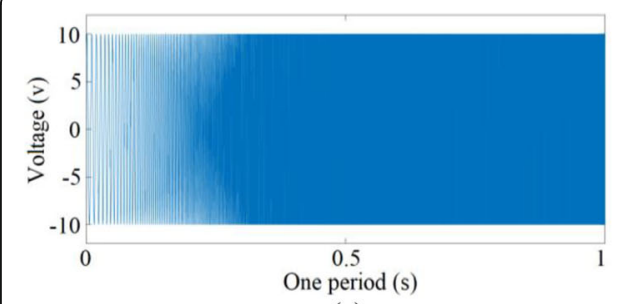

(a)



(b)

Fig. 5 Excitation signal. a: Time domain signal, b: Frequency domain signal

The stress wave signals were collected by data acquisition system NI-USB 6363, and it also can actuate the PZT transducer with a swept sine wave signal. The sweeping sinusoidal signal ranges from $100 \mathrm{~Hz}$ to $150 \mathrm{kHz}$, and the sweeping sinusoidal signal has an amplitude of $10 \mathrm{~V}$ and a period of $1 \mathrm{~s}$. Figure 5 displays the time and frequency domains of excitation signal.

\subsection{Experiment monitoring technology}

The principle of piezoceramic-based active sensing method was illustrated in Fig. 6. Before loading, the bond-slip damage does not occur, the received wave of SA sensor is a relatively strong signal, as shown in Fig. 6a, which indicates that the specimen is nondestructive. With the increase of the load, the specimen begins to suffer bond-slip damage gradually, as shown in Fig. $6 \mathrm{~b}$.

The amplitude of received signal decreases because the interface damage blocks the propagation of incident wave. When the load increases further, the interface damage become worse, and the signal of SA gradually decreases until the damage of concrete encased steel composite beam occurs.

In wavelet packet analysis, n-level wavelet packet decomposition is carried out for sensor signal $X$, and $2^{n}$ signal subsets with different frequency bands are obtained. The subset $X_{j}$ of the signal can be expressed as

$$
X_{j}=\left[X_{j, 1}, X_{j, 2}, \ldots, X_{j, m}\right]
$$

Where $m$ is the number of sampling data of decomposed signal subset and $j$ stands for the frequency band $\left(j=1, \ldots, 2^{n}\right)$. Additionally, the total energy of decomposed signal $E_{i, j}$ can be computed as:

$$
\begin{aligned}
& E_{i, j}=\left\|X_{j}\right\|^{2}=X_{j, 1}^{2}+X_{j, 2}^{2}+\ldots+X_{j, m}^{2} \\
& E_{i}=\left[E_{i, 1}, E_{i, 2}, E_{i, 2^{n}}\right]
\end{aligned}
$$

In this study, the original signal energy $\left(E_{0}\right)$ was collected in the health status of specimen. Then, as the applied force gradually increased, the bond-slip damage at the steel-concrete interface occurred and increased accordingly. Meanwhile, the signal energy $E_{i}$ received by the SA sensor continuously decreased. Finally, when the wavelet packet energy collected by SA sensor was close to zero, the steel-concrete interface was considered under the complete damage condition. 


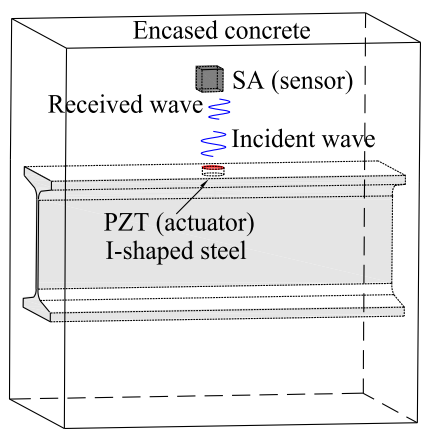

(a)



(b)

Fig. 6 Principle of piezoceramic-based active sensing method. a: Initial state before bond-slip damage, b: Bond-slip damage state

\section{Experiment results and discussion}

\subsection{Failure mode}

The damaged form of the specimen is shown in Fig. 7. According to the failure mode of the specimen, when the steel bar yields or the CFRP bar breaks, the concrete in the compression zone of the specimen is not crushed. However, the cracking of specimens shows that all the three specimens present a similar crack behavior at low loading level. When the load reaches about $15 \%$ of the peak load, the initial crack appears first, with the load increases, the number of cracks increases in the specimen. Finally, these flexural cracks expand to approximately 3/5 depth of TSA, but 4/5 depth for TSB and TSC.

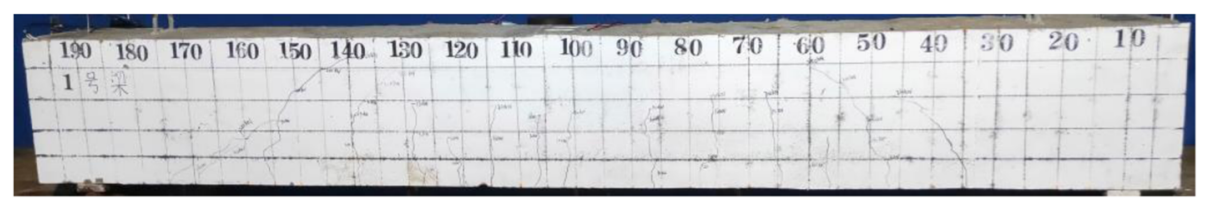

(a)

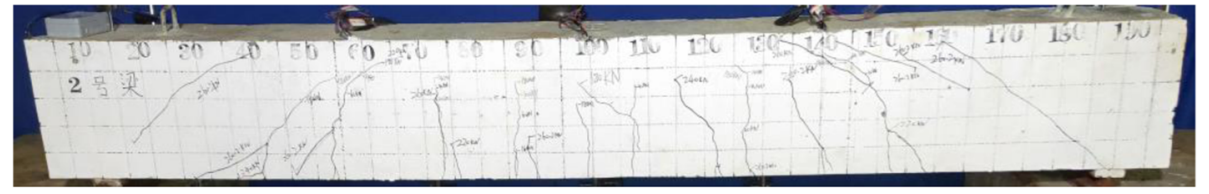

(b)

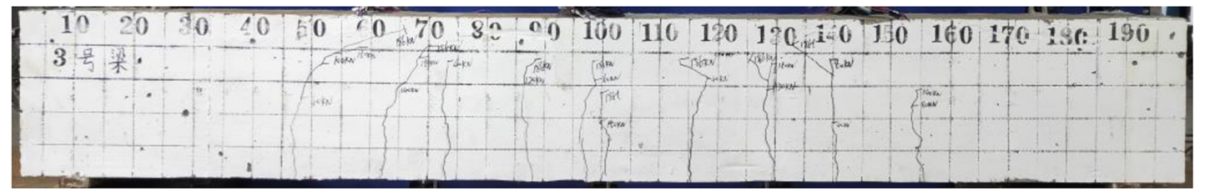

(c)

Fig. 7 Failure form of specimens. a: TSA, b: TSB, c: TSC 
The shear cracks of TSA are much smaller than TSB; The shear cracks from the support to the loading point of TSB do not form until the failure of CFRP bar occurs. However, all the cracks in TSC are flexural cracks at the beginning of loading. When the CFRP bar fails, the tips of most flexural cracks no longer extend upward with the increase of load while the shear cracks appear and extend to the loading position of steel spreader beam.

Comparison the failure figures of TSA with three $16 \mathrm{~mm}$-diameter steel bars and TSB with two $10 \mathrm{~mm}$-diameter CFRP bars, it can be seen that with the same flexural bearing capacity, the crack length of TSB is generally greater than that of TSA, this is mainly due to the larger elastic modulus of reinforcement in TSA, as shown in Fig. 7a and $\mathrm{b}$.

When the TSB and TSC are applied with the same load at low loading stage, cracks along the height of TSC are longer than those of TSB, as shown in Fig. 7b and c. This indicates that the development of cracks can be delayed and the service performance can be improved by increasing the reinforcement ratio of concrete encased steel composite beams.

\subsection{Stiffness characteristics}

The vertical displacements at beam mid-span section and loading points (left or right $1 / 4$ span section) were monitored by three dial indicators, and stiffness characteristics of specimen could be reflected by the vertical displacement of mid-span section and left or right $1 / 4$ span section under all level loads. The total applied load-vertical

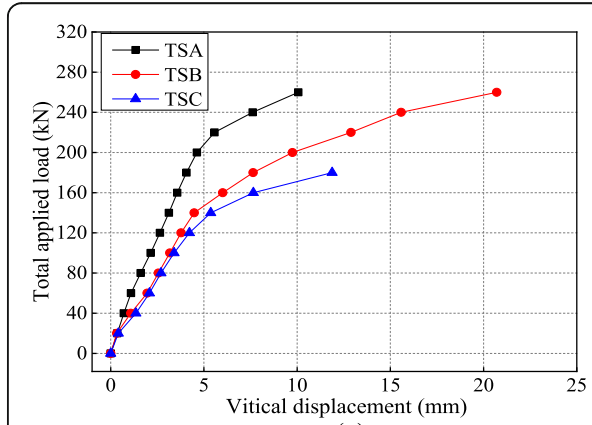

(a)



(b)



(c)

Fig. 8 Load-vertical displacement curves of specimens. a: Load-vertical displacement curves of mid span, b: Load-vertical displacement curves of left quarter span, c: Load-vertical displacement curves of right quarter span 
displacement curves of mid-span, left and right quarter spans of three specimens were shown in Fig. 8a, b and c.

When the total applied load reaches $40 \mathrm{kN}$, the slope of the load-vertical displacement curve of TSA changes. However, the curves of TSB and TSC have obvious changes at the applied load of $20 \mathrm{kN}$. This reveals that the cracking load of TSA with three $16 \mathrm{~mm}$ diameter steel bars is greater than that of TSB with two 10mm-diameter FRP bars. In addition, when two specimens are applied with the same load, the vertical displacements of mid-span and two quarter spans of TSA are smaller than those of TSB. This is mainly because TSA and TSB have different elastic moduli, and the elastic modulus of steel bars is large than that of CFRP bars. As a result, the flexural stiffness of concrete steel-encased composite beam is larger than that of CFRP-reinforced concrete steel-encased composite beam.

For TSB and TSC, their load-vertical displacement curves are similar in elastic stage. After cracks appear in both beams, the vertical displacements of mid-span and two quarter spans of TSC are larger than those of TSB under the same load level; The vertical displacement difference between spans of TSB and TSC becomes larger as the load increases. This indicates that the flexural stiffness of cracked TSC decreases faster than that of TSB. Compared with TSC, TSB has the same contact area between CFRP bars and concrete, but larger reinforcement ratio. This is mainly because the flexural behavior of uncracked beams is determined by the total moment of inertia of concrete section. After cracking, the flexural stiffness of specimens mainly depends on the ratio of reinforcement. Therefore, the CFRP-reinforced concrete steel-encased composite beams with higher reinforcement ratio have greater flexural stiffness and smaller deflection under the same load level.

\subsection{Bond-slip characteristics}

The bond-slip of two beam ends was quantified by the relative displacement between the end of I-shaped steel beam and encased concrete. Different from the traditional method, two bond-slip monitoring sensors were used to monitor the slippage at both

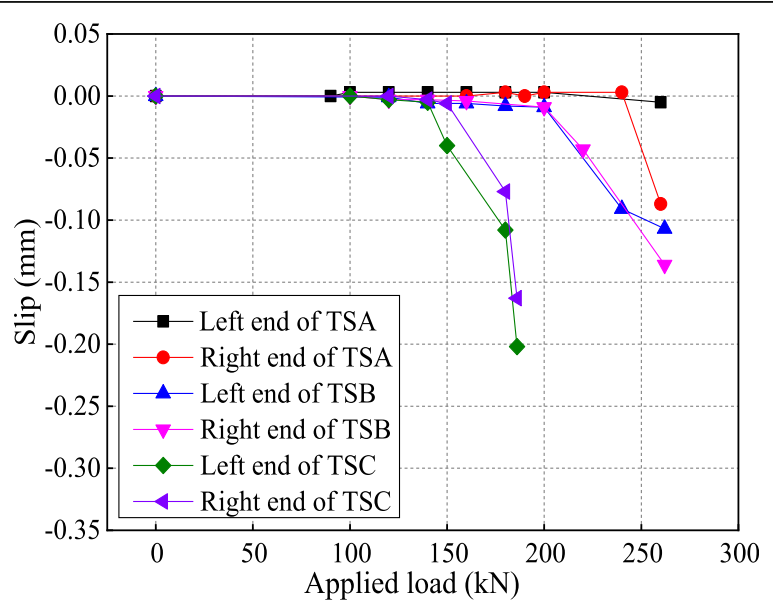

Fig. 9 Load- slip curves at the ends of specimens 
ends of specimen in real time. The load-slip curves of ends of three specimens were obtained from the test results, as shown in Fig. 9.

From the comparison of load-slip curves of TSA and TSB, it can be found that the bond-slip damage at the ends of TSA starts to be around $240 \mathrm{kN}$ while the obvious bond-slip damage occurs around $200 \mathrm{kN}$ for TSB. The main reason is that the elastic modulus of steel bars in TSA larger than of the CFRP bars in TSB, which makes the flexural stiffness of TSA larger than that of TSB with the same flexural capacity. From the Fig. 9, it can be seen that the slip of left end of TSA only is $0.005 \mathrm{~mm}$ when the specimen fails, while the slip at the right end is about $0.087 \mathrm{~mm}$. The is mainly due to the large flexural stiffness of TSA, which results in small slip on the left and right ends, and less than $0.1 \mathrm{~mm}$. In addition, the loading device is slightly unbalanced when the TSA loads, and there is a difference in the amount of slip between the left and right ends.

By comparing the curves of TSB and TSC, it can be found that the bond-slip damage of TSC occurs earlier than that TSB. During the experimental loading process, the bond-slip damage of the TSC begins to occur at the loading level of $120 \mathrm{kN}$ and causes a sharp increase at the loading level of $150 \mathrm{kN}$. However, the most obvious bond-slip damage of TSB occurs at the applied load of $200 \mathrm{kN}$, and the largest slip of TSB is smaller than that of TSC. Therefore, in the case of the same contact area between the main bar and concrete, the resistance capacity to bond-slip and the service performance of new composite beam can be improved by increasing the reinforcement ratio.

\subsection{Bond-slip damage monitoring}

\subsubsection{Time domain analysis}

The response signals of the sensors of each specimen were collected and analyzed in the time domain. To describe the bond-slip damage process of concrete encased steel composite specimen, five sensors named SA1 SA5 were installed in the specimen. In the follow analysis, six typical work conditions of TSA were selected as the analysis object: (a) $0 \mathrm{kN}$; (b) $40 \mathrm{kN}$; (c) $80 \mathrm{kN}$; (d) $120 \mathrm{kN}$; (e) $160 \mathrm{kN}$; (f) $200 \mathrm{kN}$. The time domain signals of sensor SA1and SA2 in TSA are shown in Figs. 10 and 11. Figure 12a-c give the time signal peak of sensors SA1 SA5 of TSA, TSB and TSC.

It can be seen from Figs. 10, 11 and 12 that the amplitude of signal in time domain decreases with the increase of load. However, the difference of time domain signals at





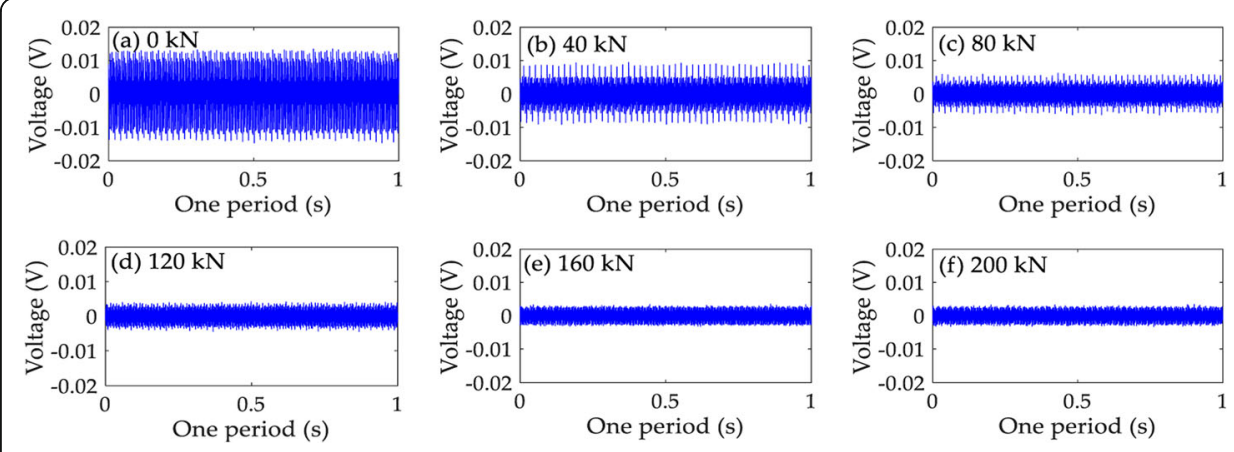

Fig. 11 Time domain signals of sensor SA2 of TSA

different loading cases, especially after bond-slip damage occurs, is not significant. There is a shape decrease at the early stage of the SA3 in TSB in Fig. 12(b). This is mainly due to the difference in the manufacturing process of PZT and SA, which enables SA3 to receive stronger signals compared to other sensors. So the downward trend of SA signal amplitude is more obvious. In addition, the peak signal of SA4 increases when the value of the applied load between $120 \mathrm{kN}$ and $160 \mathrm{kN}$ in Fig. 12(c). This may be caused by noise errors in the monitoring environment, its influence is negligible, especially for the subsequent frequency domain analysis and wavelet packet energy analysis.

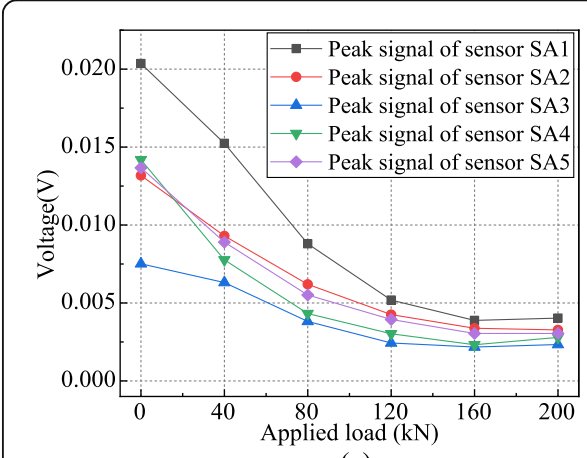

(a)

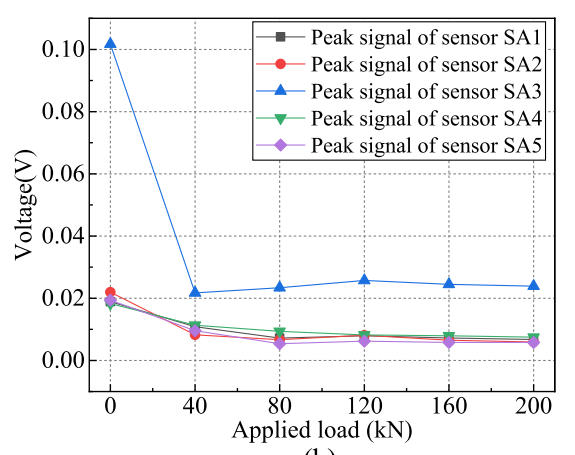

(b)

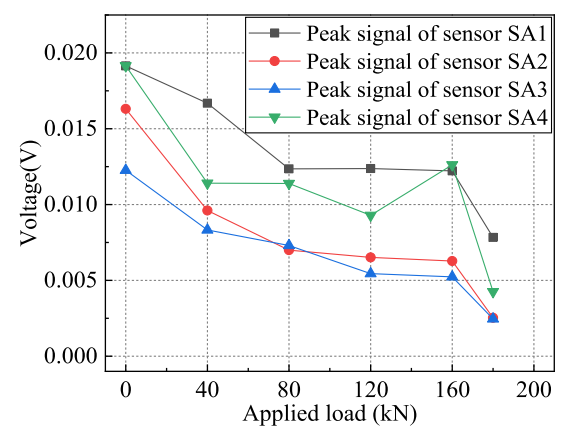

(c)

Fig. 12 Load-peak of time signal of sensors in specimens. a: TSA, b: TSB, c: TSC 


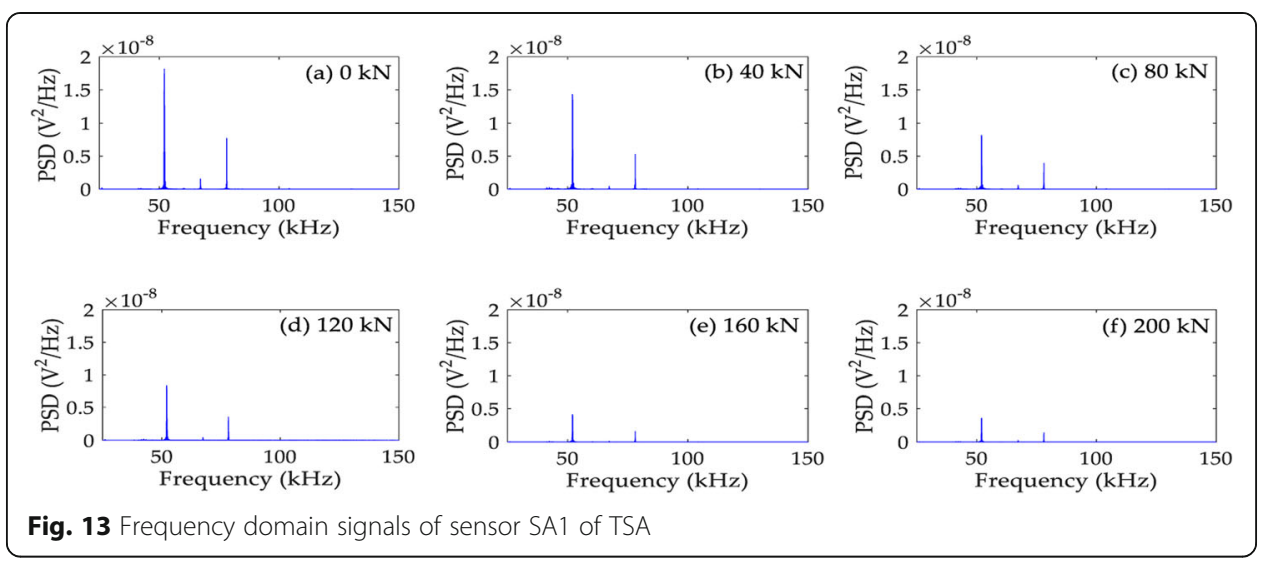

\subsubsection{Frequency domain analysis}

Based on the time domain analysis, the frequency domain signals collected by SA sensors was analyzed, and the bond-slip damage was reflected by the change of power spectra density (PSD) energy of response signal. The frequency domain signals received by sensors SA1 and SA2 of TSA were shown in Figs. 13 and 14, respectively.

The frequency domain signal of TSA shows that the sensitive frequency of stress wave to bond-slip is between $50 \mathrm{kHz}$ to $80 \mathrm{kHz}$, that is, the maximum frequency domain amplitude of each sensor appears in this frequency range. It can be seen from the amplitude of the frequency domain signal that the signal amplitude of the specimen decreases with the gradual increase of the loading load.

The load-peak PSD curves of sensors SA1 to SA5 in TSA, TSB and TSC were shown in Fig. 15a, b and c, respectively. By comparing the amplitude of signals in frequency domain, it can be observed that the signal amplitudes of three specimens decrease with the gradual increase of applied load. Moreover, the signal amplitude attenuation of TSB is faster than that of TSA, mainly reason the elastic modulus of steel bar of TSA is greater than TSB. Therefore, TSA has larger flexural stiffness and better bond-slip resistance than TSB with the same flexural capacity.

Comparing the signal amplitudes of SA1 and SA3 in TSB and TSC with the total applied load of $40 \mathrm{kN}$, it can be clearly found that the frequency domain
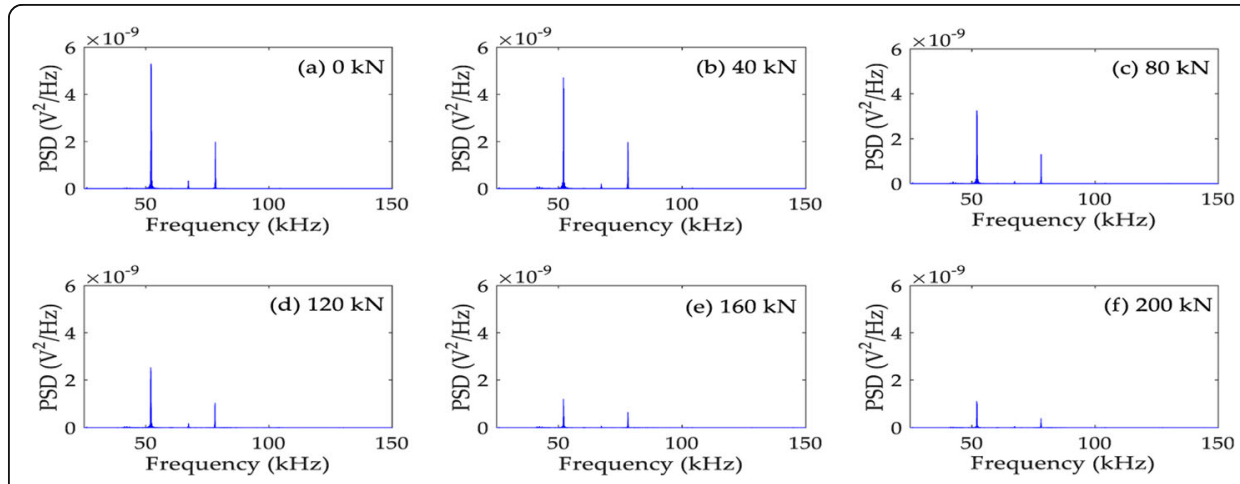

Fig. 14 Frequency domain signals of sensor SA2 of TSA 


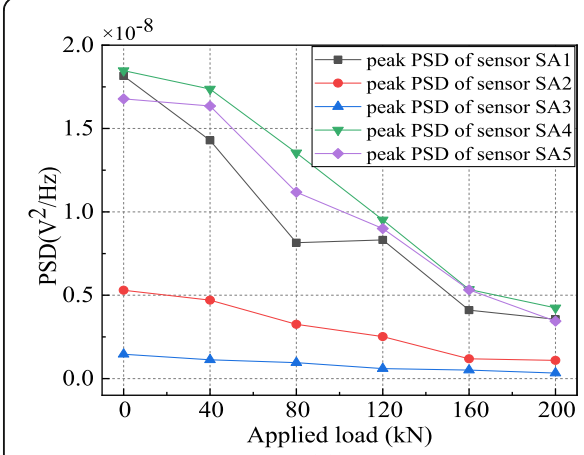

(a)

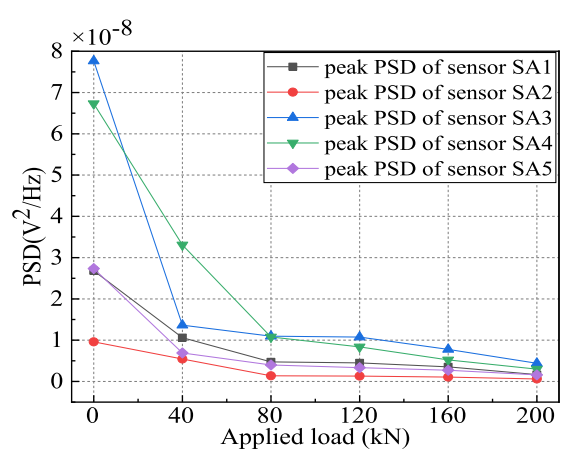

(b)

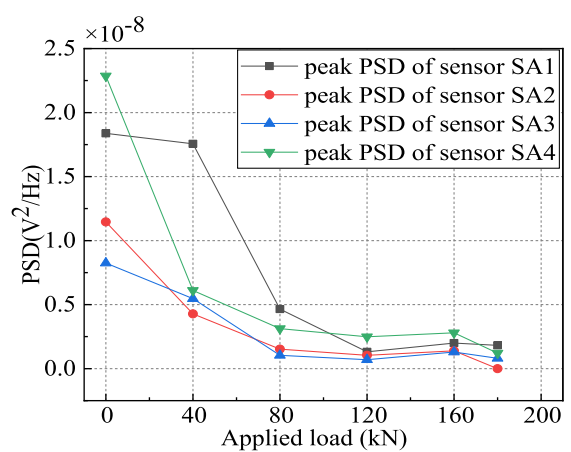

(c)

Fig. 15 Load-peak PSD curves of sensors in specimens. a: TSA, b: TSB, c: TSC

signal amplitudes of SA1 and SA3 in TSB decrease faster than those of TSC at the low loading level, as shown in Fig. 15b and c. However, there is no significant difference in the frequency signals of SA2 and SA4 of TSB and TSC. The mainly reason is that when the contact area between the main bars and concrete is identical, the distributed arrangement of CFRP bars in TSC can delay the bond-slip process and improve the bond-slip resistance of the concrete steelencased composite beams.

\subsubsection{Wavelet packet energy analysis}

In order to explore a more sensitive method to bond-slip damage of the specimens, on the basis of the previous time-and frequency-domain analysis, the wavelet packet energy is proposed. The wavelet packet energy analysis of TSA and TSB sensor is taken as an example to illustrate its recognition effect of bond-slip damage process.

The wavelet packet energy of sensors in TSA were show in Fig. 16. For two sensors located at the upper and lower flanges of ends of TSA, when the load reaches $20 \mathrm{kN}$, the energy of SA1 and SA5 decreases by $45.9 \%$ and $84.7 \%$, as show in Fig. 16a, and e. The results show that the bond-slip damage of lower flange at the end of TSA is more severe than that of upper flange at the low load level, which is consistent with the slip value at two ends of beam measured by the bond-slip sensors.

The wavelet packet energy of SA2 and SA4 were analyzed, as show in Fig. 16b and d. It can be found that when the applied load reaches $20 \mathrm{kN}$, the wavelet packet energy of SA2 is reduced by $86.4 \%$, while the wavelet packet energy of SA4 is reduced by only 


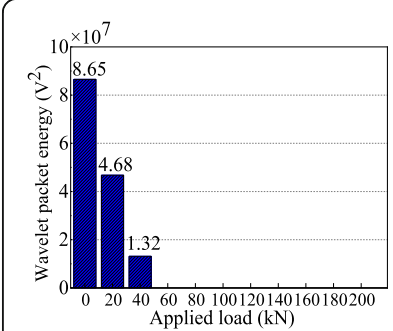

(a)

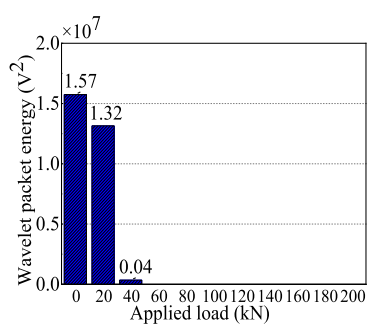

(d)

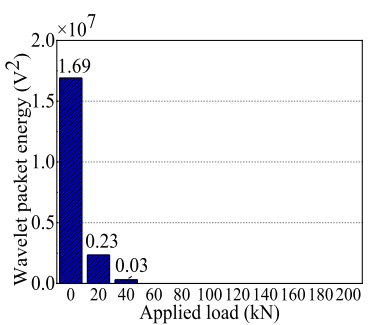

(b)



(c)

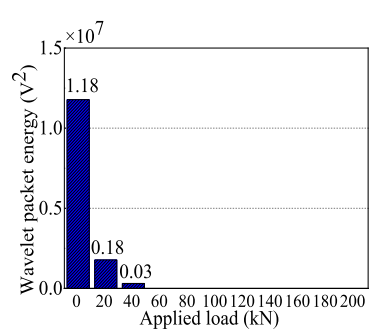

(e)

Fig. 16 Wavelet packet energy analysis of sensors of TSA. a: The sensor SA1 of TSA, $\mathbf{b}$ : The sensor SA2 of TSA, $\mathbf{c}$ : The sensor SA3 of TSA, $\mathbf{d}$ : The sensor SA4 of TSA, e: The sensor SA5 of TSA

$16.6 \%$. In addition, the wavelet packet energy of SA2 attenuates faster than that of SA3, this is mainly due to the stress concentration caused by the applied load near the $1 / 4$ span I-shaped steel beam, where the bond-slip damage develops rapidly than that of lower flange of mid span.

The wavelet packet energy of sensors in TSB and TSA were compared, as shown in Fig. 17. It shows wavelet packet energy of most sensors in TSB decreases by about $90 \%$ when the applied load reaches $20 \mathrm{kN}$, while it decreases by $80 \%$ at $40 \mathrm{kN}$ in TSA. It implies that the flexural stiffness of TSA can be improved by applying the main bars with

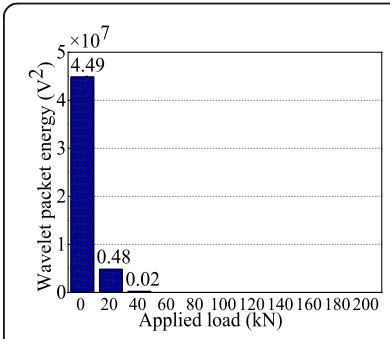

(a)

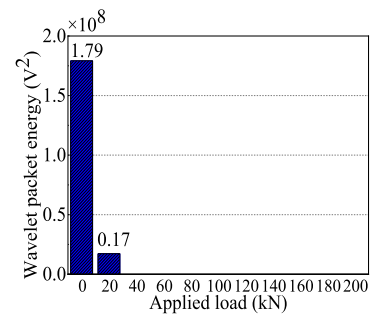

(b)

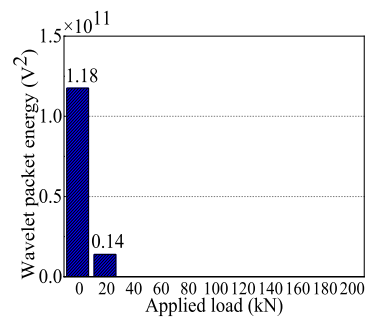

(c)



(d)

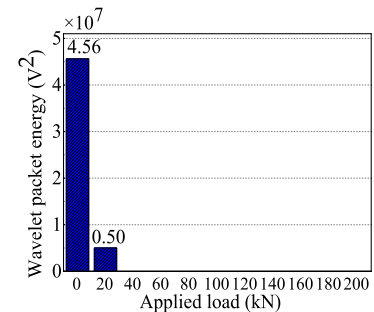

(e)

Fig. 17 Wavelet packet energy analysis of sensors of TSB. a: The sensor SA1 of TSB, $\mathbf{b}$ : The sensor SA2 of TSB, $\mathbf{c}$ : The sensor SA3 of TSB, $\mathbf{d}$ : The sensor SA4 of TSB, e: The sensor SA5 of TSB 
larger elastic modulus, and its bond-slip resistance is better than that of TSB with the same flexural capacity.

As can be seen from the figures, with the increase of load, the wavelet packet energy of the specimen decreases continuously. When the load reaches a certain level, the wavelet packet energy is completely attenuated and can even be ignored. The main reason is that the relative displacement happens between the Ishaped steel beam and encased concrete after the bond-slip damage occurs, which blocks the propagating stress wave from the I-shaped steel flange to the encased concrete.

\section{Conclusions}

Three RCESC beams reinforced with steel bars or CFRP bars were designed and fabricated. A piezoelectric-based active sensing method was studied the bond-slip behaviors between the I-shaped steel and CFRP reinforced concrete and the damage states of the beams. The main findings are summarized as follows:

(1) The CFRP bars in specimens can delay the bond-slip process and improve the bond-slip resistance of the concrete steel-encased composite beams, when the contact area between the main bars and concrete is identical.

(2) Based on the experimental results, it can be found that the flexural stiffness can be improved by applying the main bars with larger elastic modulus, and better bondslip resistance can be obtained based on the same flexural capacity.

(3) The specimens with higher reinforcement ratio have greater flexural stiffness and smaller deflection under the same load level. Therefore, the bond-slip behavior of the composite beam can be improved by increasing reinforcement ratio.

(4) The bond-slip damage process could be monitored by the proposed method. When the bond-slip damage occurs, the amplitude of the signal in time-and frequencydomain and wavelet packet energy decrease obviously.

(5) Compared with time-and frequency-domain analyses, the wavelet packet energy analysis can reflect the slip damage process of interface more intuitively. Meanwhile, it can identify and evaluate the bond-slip damage of the interface of the specimens.

\section{Abbreviations}

CFRP: Carbon fiber reinforced polymer; RCESC: Reinforced concrete encased steel composite; PZT: Lead zirconate titanate; SAs: Smart aggregates; ECC: Engineering cementitious composites; GFRP: Glass fiber reinforced polymer; TSA: Test specimen A; TSB: Test specimen B; TSC: Test specimen C; PSD: Power spectra density

\section{Acknowledgements}

Thanks to our colleagues at Changsha University of Technology \& Science for their assistance and discussions.

\section{Authors' contributions}

Conceptualization, Tianyong Jiang; Formal analysis, Lei Wang; Investigation, Donghai Yu, Min Xiao and Lingyun Li; Supervision, Tianyong Jiang and Lei Wang; Writing-original draft, Tianyong Jiang, Donghai Yu, Min Xiao, and Lingyun Li; Writing-review \& editing, Tianyong Jiang and Lei Wang. All authors have read and agreed to the published version of the manuscript. The author(s) read and approved the final manuscript. 
Availability of data and materials

The data and materials in current study are available from the corresponding author on reasonable request.

\section{Declaration}

Competing interests

The authors declare that they have no competing interests.

\section{Author details}

${ }^{1}$ School of Civil Engineering, Changsha University of Science and Technology, Changsha, China. ${ }^{2}$ Shenzhen Expressway Co., Ltd, Shenzhen, China.

Received: 23 May 2021 Accepted: 18 June 2021

Published online: 16 August 2021

\section{References}

Abouhussien AA, Hassan AAA (2017) Acoustic emission-based analysis of bond behavior of corroded reinforcement in existing concrete structures. Struct. Control Health Monit 24(3):1893

Brisotto DDS, Bittencourt E, Bessa VMRD (2012) Simulating bond failure in reinforced concrete by a plasticity model. Comput Struct 106-107:81-90

Chen CC, Sudibyo T (2018) Behavior of partially concrete encased steel beams under cyclic loading. Int J Steel Struct 19(1):1-14

Chen CC, Sudibyo T (2018) Effect of intermediate stiffeners on the behaviors of partially concrete encased steel beams. Adv Civil Eng 2018:1-15

Chen L, Dai J, Jin Q, Chen L, Liu X (2015) Refining bond-slip constitutive relationship between checkered steel tube and concrete. Constr Build Mater 79:153-164

Chen Y, Li W, Fang C (2017) Performance of partially encased composite beams under static and cyclic bending. Structures 9 : 29-40

Dai LZ, Chen Y, Wang L, Ma YF (2021) Secondary anchorage and residual prestressing force in locally corroded PT beams after strand fracture. Constr Build Mater 275:122137

Ge WJ, Ashour AF et al (2019) Experimental study on flexural behavior of ECC-concrete composite beams reinforced with FRP bars. Comp Struct 208:454-465

Giri P, Mishra S, Clark SM, Samali B (2019) Detection of gaps in concrete-metal composite structures based on the feature extraction method using piezoelectric transducers. Sensors 19:1769

Hiasa S, Catbas FN, Matsumoto M, Mitani K (2016) Monitoring concrete bridge decks using infrared thermography with high speed vehicles. Struct Monit Maintenance 3:277-296

Ho SCM, Ren L, Labib E, Kapadia A, Mo YL, Li H, Song G (2015) Inference of bond slip in prestressed tendons in concrete bridge girders. Struct Control Health Monit 22(2):289-300

Huo L, Li C, Jiang T, Li H (2018) Feasibility study of steel bar corrosion monitoring using a piezoceramic transducer enabled time reversal method. Appl. Sci 8(11):2304

Jiang A, Chen J, Jin W (2013) Experimental study of innovative steel-concrete composite beams under hogging moment. Adv Struct Eng 16(5):877-886

Jiang T, Kong Q, Patil D, Luo Z, Huo L, Song G (2017) Detection of debonding between fiber reinforced polymer bar and concrete structure using piezoceramic transducers and wavelet packet analysis. IEEE Sens 17:1992-1998

Jiang Y, Hu X, Hong W, Gu M, Sun W (2017) Investigation on partially concrete encased composite beams under hogging moment. Adv Struct Eng 20(3):461-470

Jiang T, Wu Q, Wang L, Huo L, Song G (2018) Monitoring of bolt looseness-induced damage in steel truss arch structure using piezoceramic transducers. IEEE Sens 18:6677-6685

Jiang T, Zhang Y, Wang L, Zhang L, Song G (2018) Monitoring fatigue damage of modular bridge expansion joints using piezoceramic transducers. Sensors 18(11):3973

Kim B, Doh JH, Yi CK, Lee JY (2013) Effects of structural fibres on bonding mechanism changes in interface between GFRP bar and concrete. Compos Part B 45:768-779

Kong Q, Robert RH, Silva P, Mo YL (2016) Cyclic crack monitoring of a reinforced concrete column under simulated pseudodynamic loading using piezoceramic-based smart aggregates. Appl Sci 6(11):341

Li X, LV. H X, Zhou (2011) Flexural behavior of GFRP-reinforced concrete encased steel composite beams. Constr Build Mater 28(1):255-262

Majdi Y, Punurai S (2014) Local bond-slip behavior between cold-formed metal and concrete. Eng Struct 69:271-284

Martinelli E, Caggiano A (2014) A unified theoretical model for the monotonic and cyclic response of FRP strips glued to concrete. Polymers 6:370-381

Qin F, Kong Q, Li M, Mo YL, Song G (2015) Bond slip detection of steel plate and concrete beams using smart aggregates. Smart Mater Struct 24(11):1-13

Renshaw JB, Lhota JR, Muthu N, Shepard SM (2015) Thermographic inspection of pipes, tanks, and containment liners, AIP Conf. Proc 1650:290-297

Rucka M (2018) Failure monitoring and condition assessment of steel-concrete adhesive connection using ultrasonic waves. Appl Sci 8(3):320

Wang L, Dai L, Bian H, Ma Y, Zhang J (2019) Concrete cracking prediction under combined prestress and strand corrosion. Struct Infrastruct Eng 15(3):285-295

Weng CC, Yen SI, Jiang MH (2002) Experimental study on shear splitting failure of full-scale composite concrete encased steel beams. J Struct Eng 128(9):1186-1194

Xu K, Deng Q, Cai L, Ho SC, Song G (2018) Damage detection of a concrete column subject to blast loads using embedded piezoceramic transducers. Sensors 18(5):1-16 
Yao D, Jia J, Wu F, Yu. F (2014) Shear performance of prestressed ultra-high strength concrete encased steel beams. Constr Build Mater 52:194-201

Yao P, Kong Q, Xu K, Jiang T, Huo L, Song G (2016) Structural health monitoring of multi-spot welded joints using a lead zirconate titanate based active sensing approach. Smart Mater Struct 25(1):015031

Zhang L, Zheng Y, Hu S, et al (2020) Identification of Bond-Slip Behavior of GFRP-ECC Using Smart Aggregate Transducers. Front Mater 7(165):1-14

Zheng Y, Zhang LF, Xia LP (2018a) Investigation of the behavior of flexible and ductile ECC link slab reinforced with FRP. Construct Build Mater 166:694-711

\section{Publisher's Note}

Springer Nature remains neutral with regard to jurisdictional claims in published maps and institutional affiliations.

Submit your manuscript to a SpringerOpen ${ }^{\odot}$ journal and benefit from:

- Convenient online submission

- Rigorous peer review

- Open access: articles freely available online

- High visibility within the field

- Retaining the copyright to your article

Submit your next manuscript at $\boldsymbol{\nabla}$ springeropen.com 